\title{
Paris, Bibliothèque nationale de France, gr. 2507
}

Costantinopoli, XIV secolo.

ff. I-VI, 206, I'-VI'; sul f. III sono registrate le segnature più antiche (Codex Telleriano Remensis 77 e Reg. 3214); sul f. VI si trovano due pinakes in greco e in latino di mano di Sevin; sul marg. inf. del f. 1r si legge la scritta che testimonia della donazione del

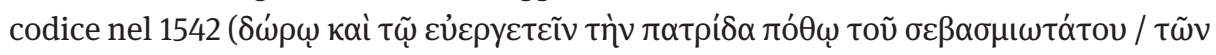

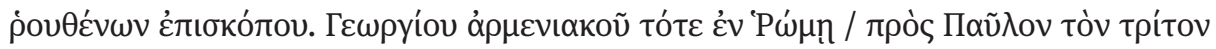

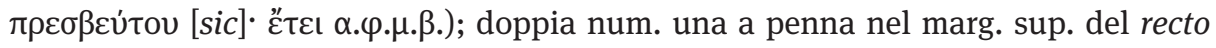
di ogni foglio e un'altra a matita nel marg. inf. int.; cart.; ff. 1-24, 33-39, 42, 47 simile a huchet (M/Tr nr. 4857, 1376), ff. 25-31, 176-206 simile a $\operatorname{arc~(M/Tr} \mathrm{nr} .367,1370)$, ff. 43-46, 49-133 basilic (M/Tr nr. 1021, 1376), ff. 135-142, 144-175 simile a trois monts (M/

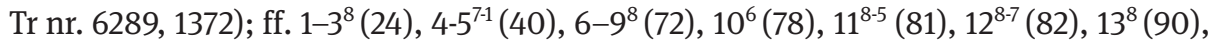
$14^{8-1}(97), 15^{7-1}(105), 16-17^{8}(121), 18^{8-4}(125), 19^{8}$ (133), $20^{10}$ (143), 21-26 (191), $27^{8-1}$ (198), $28^{8}$ (206); num. fasc. nel marg. inf. est. del verso dell'ultimo foglio di alcuni fascicoli, resta traccia di $\beta^{\prime}$ (f. 82v), ı $\varepsilon^{\prime}$ (f. 183v) e ı $\zeta^{\prime}$ (f. 198v); mm $216 \times 144=20 / / 150 / / 45 \times 20 / /$ 90 // 31; a piena pagina, 36 1l./36 rr., unità di rigatura $\mathrm{mm} 5$, rigatura tracciata a secco, tipo S/L 00D1 (Muz 1-1/0/0/J); sono bianchi i ff. 32, 39v-40v, 104, 134, 141v-143v, 201v202v. Legatura in marocchino rosso, divisa in cinque riquadri, su cui sono impresse in oro le iniziali di Luigi Filippo e il contenuto del codice.

\section{Scrittura}

Nel codice è possibile riconoscere un solo copista: <Isacco Argiro (Mondrain 2007 [2008] 167)> (ff. 1r-206v).

\section{Decorazione}

Rubricatio in inchiostro carminio realizzata da Argiro.

\section{Contenuto}

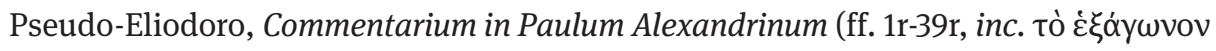

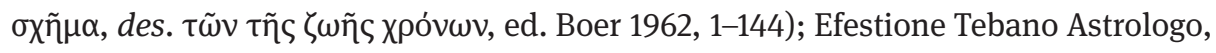

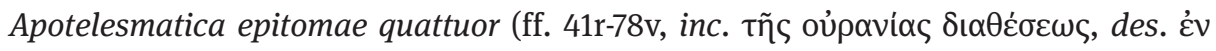

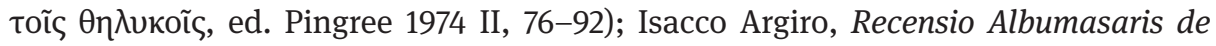

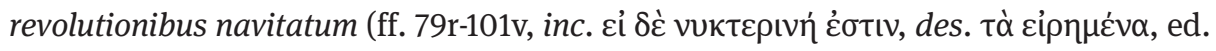


Pingree 1968, 112-248); Retorio, Compendium astrologicum (ff. 101v-113v, 1. 10, inc.

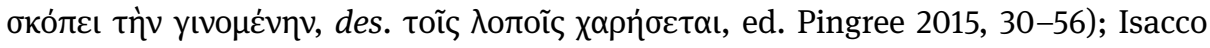
Argiro, Recensio Albumasaris de revolutionibus navitatum (ff. 113v, 1. 11-134r, inc.

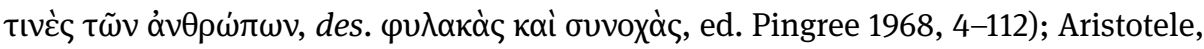

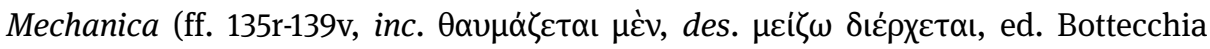

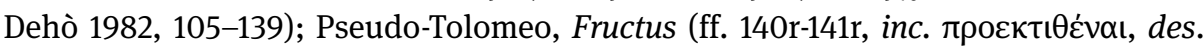

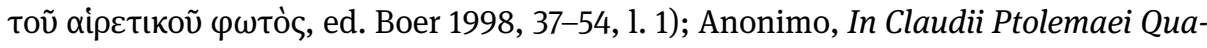

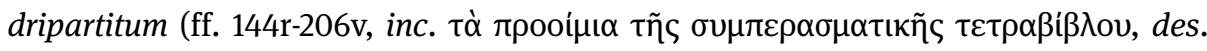

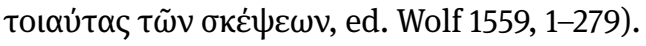

\section{Relazioni stemmatiche}

Il codice raccoglie una miscellanea di testi astrologici, tra cui la recensio $\mathbf{p}$ del De revolutionibus di Albumasar realizzata da Argiro sulla base del Vat. gr. 191 e erroneamente attribuita a Isidoro di Kiev (Omont 1888, 274); alcuni frammenti di questa recensione sono tramandati anche nel Vat. gr. 1698 (Pingree 1968, XI-XII). Argiro è intervenuto largamente anche sul testo dei Mechanica di Aristotele, di cui restituisce una versione più ampia dell'originale: è una sorta di parafrasi del testo aristotelico, volta a spiegare alcuni problemi meccanici e composta, probabilmente, per uso scolastico (Bottecchia Dehò 1975, 52). Relativamente ai Mechanica il codice è antigrafo del Marc. gr. Z. 215 (coll. 752).

\section{Storia del codice}

Nel 1542 l'esemplare divenne di proprietà di Georges d'Armagnac, ambasciatore del re di Francia presso la sede apostolica (nota al f. 1r). Dopo essere passato per le mani di Carol de Montchal, successore di d'Armagnac all'episcopato di Tolosa, è confluito nella collezione libraria dell'arcivescovo di Reims, Charles-Maurice Le Tellier, dove figura con il nr. 77. Questa collezione passò alla corona di Francia nel 1700 (Muratore 2009 I, 103, n. 39).

\section{Bibliografia}

\section{Cataloghi}

CCAG VIII, 45-65; Omont (1888) 274. 


\section{Edizioni}

Boer (1962); Boer (1998); Bottecchia Dehò (1982); Pingree (1968); Pingree (1974); Pingree (2015); Wolf (1559).

\section{Codicologia e paleografia}

Bottecchia Dehò (1975) 43-52; Caballero Sánchez (2013) 94-99; Mondrain (2007) [2008] 167; Muratore (2009) I, 103 n. 39.

\section{Riproduzioni}

Bottecchia Dehò (1975) tavv. 1-2. 